\title{
MicroRNA Profile of Granulosa Cells after Ovarian Stimulation Differs According to Maturity of Retrieved Oocytes
}

\author{
Die MicroRNA-Profile von Granulosazellen nach ovarieller Stimulation \\ unterscheiden sich je nach Reife der entnommenen Eizellen
}

Authors

Affiliations
Y. J. Kim¹, S.-Y. Ku², Y. Y. Kim² , C. S. Suh², S. H. Kim², Y. M. Choi ${ }^{2}$

${ }^{1}$ Department of Obstetrics and Gynecology, Korea University Guro Hospital, Korea University College of Medicine, Seoul, South Korea

${ }^{2}$ Department of Obstetrics and Gynecology, Seoul National University College of Medicine, Seoul, South Korea

\section{Key words \\ - microRNA \\ - human granulosa cell \\ - follicular fluid \\ - oocyte maturation \\ in vitro fertilization \\ Schlüsselwörter \\ - microRNA \\ menschliche Granulosazelle \\ - Follikelflüssigkeit \\ - Eireifung \\ - In-vitro-Fertilisation}

\section{Abstract \\ $\nabla$}

Background: Recent animal studies demonstrated that regulating the microRNA (miRNA) in granulosa cells (GCs) modulates the meiotic competence of oocytes. However, the difference in expression profiles of miRNAs in human GCs according to the maturity of the oocyte still remains to be elucidated.

Objective: This observational study investigated whether the miRNA profile of human GCs differs according to the maturity of the retrieved oocyte after controlled ovarian stimulation for in vitro fertilization (IVF).

Methods: Ten women who underwent ovarian stimulation cycles with GnRH agonist long protocols were recruited. The follicular fluid (FF) from dominant follicles was individually aspirated at oocyte retrieval. Oocytes were divided into two groups according to oocyte maturity ("mature group" vs. "immature group"). GCs were collected from the FF and miRNA was analyzed using realtime PCR.

Results: Mean number of MII oocytes in the mature group was $1.6 \pm 0.9$ with none in the immature group $(p=0.008)$. Mean number of MI oocytes was $5.6 \pm 2.1$ in the mature group and $1.0 \pm 0.0$ in the immature group $(\mathrm{p}=0.008)$. The total number of retrieved oocytes was $8.8 \pm 1.9$ in the mature group and $2.0 \pm 1.2$ in the immature group ( $p=0.008)$. The GCs of the mature group showed a significantly lower expression of hsalet-7b compared to the GCs of the immature group ( $\mathrm{p}<0.001)$.

Conclusion: Taken together, the miRNA expression profiles of human GCs obtained from dominant follicles are associated with maturity of the adjacent oocyte and may be useful as a prognosticator of IVF outcome.

\section{Zusammenfassung \\ $\nabla$}

Hintergrund: Einige kürzlich unternommene Tierversuche haben gezeigt, dass die Regulierung der MicroRNA (miRNA) in Granulosazellen die meiotische Kompetenz von Eizellen beeinflusst. Aber die Unterschiede im Expressionsprofil der MiRNA von menschlichen Granulosazellen und deren Zusammenhang mit dem Reifungsgrad der Eizelle sind noch unzureichend geklärt.

Ziel: Ziel dieser Beobachtungsstudie war es, zu untersuchen, ob es Unterschiede in den miRNAProfilen menschlicher Granulosazellen gibt nach der kontrollierten ovariellen Stimulation für die In-vitro-Fertilisation (IVF).

Methoden: In die Studie eingeschlossen wurden 10 Frauen, die mit GnRH-Agonisten zur ovariellen Stimulation behandelt wurden (langes Protokoll). Die Follikelflüssigkeit des dominanten Follikels wurde bei der Eizellentnahme ebenfalls abgesaugt. Die entnommenen Eizellen wurden je nach Reifegrad in 2 Gruppen unterteilt („ausgereifte Gruppe“ vs. „nicht ausgereifte Gruppe“). Es wurden dann Granulosazellen aus der Follikelflüssigkeit gesammelt und deren miRNA mit der Echtzeit-PCR-Methode analysiert.

Ergebnisse: Die durchschnittliche Anzahl MIIOozyten in der ausgereiften Gruppe betrug $1,6 \pm 0,9$, während die nicht ausgereifte Gruppe keine MII-Oozyten aufwies ( $p=0,008$ ). Die durchschnittliche Anzahl MI-Oozyten betrug 5,6 $\pm 2,1$ in der ausgereiften Gruppe und 1,0 $\pm 0,0$ in der nicht ausgereiften Gruppe $(p=0,008)$. Die Gesamtzahl entnommener Eizellen betrug $8,8 \pm 1,9$ in der ausgereiften Gruppe und 2,0 $\pm 1,2$ in der nicht ausgereiften Gruppe ( $\mathrm{p}=0,008)$. Die Granulosazellen der ausgereiften Gruppe wiesen eine signifikant niedrigere Expression von hsa-let-7b auf verglichen mit den Granulosazellen der nicht ausgereiften Gruppe ( $\mathrm{p}<0,001)$. 
Schlussfolgerung: Die MiRNA-Expressionsprofile menschlicher Granulosazellen aus dominanten Follikeln korrelieren mit der Reife des Oozyten. Diese Erkenntnis könnte nützliche Hinweise für die Prognose hinsichtlich des Erfolgs einer IVF-Behandlung liefern.

\section{Introduction}

$\nabla$

Although outcomes after in vitro maturation (IVM) have improved in recent years and are now clinically acceptable, obtaining meiotically competent oocytes (metaphase II, MII) is an essential precondition for optimal in vitro fertilization (IVF). The meiotic competence of oocytes depends on the potential of the respective follicles which support the oocytes' maturation $[1,2]$. During the process of oocyte development, ovulation and fertilization, each oocyte is usually surrounded by several layers of granulosa cells (GCs). GCs play an important role as mediators of follicular potential by communicating with oocytes via oocyte paracrine signals $[3,4]$. During ovarian stimulation in IVF cycles, many genes expressed on GCs have been described as being controlled by both maternal and oocyte-derived signals, and it has been suggested that GCs may provide information about the maturation competence of their associated oocytes [5-7].

MicroRNAs (miRNAs) are endogenously produced non-coding RNA molecules that post-transcriptionally regulate gene expression by inhibiting the translation or cleaving of complementary target messenger RNAs (mRNAs) by binding to 3' untranslated regions (UTR) $[8,9]$. Since the discovery of miRNA (lin-4) in Caenorhabditis elegans [10], miRNAs have been shown to play an important role in cellular signaling, apoptosis, metabolism, development and organogenesis [11-15]. Our recent study demonstrated that regulating miRNA in GCs can modulate the meiotic competence of oocytes during in vitro maturation in a mouse follicles model [16]. The results implied that oocyte maturation could be influenced by the miRNA profile of adjacent GCs. However, differences in the expression profiles of miRNAs in human GCs according to the maturity of their associated oocytes still remain to be elucidated.

This study aimed to evaluate the miRNA expression profiles of human GCs and to detect differences between the miRNA expression of GCs of human MII oocytes and that of MI oocytes using follicular fluid (FF) obtained during oocyte retrieval in IVF cycles.

\section{Materials and Methods}

\section{The subjects}

Ten women who underwent ovarian stimulation cycles with GnRH agonist long protocols were recruited. All subjects presented with unexplained infertility. As a first step, pituitary downregulation was initiated by the injection of triptorelin (decapeptyl depot, $1.88 \mathrm{mg}$; Ferring, Sweden) from the mid-luteal phase of the previous cycle. For controlled ovarian stimulation, administration of 150-300 IU of FSH (Gonal-F; Serono, Geneva, Switzerland), depending on the expected response, was started on day 3 of the menstrual cycle and continued until the leading follicle had a mean diameter of $17 \mathrm{~mm}$. Recombinant human chorionic gonadotropin (hCG) (Ovidrel, Serono, Geneva, Switzerland) was injected subcutaneously 36 hours before transvaginal oocyte retrieval. No serious complications were reported during ovarian stimulation or after oocyte retrieval.
FF was individually aspirated in each patient during oocyte retrieval from the first accessible dominant follicle. The maturation of the retrieved oocytes was recorded for each FF sample. After centrifugation of FF, human GCs were collected from five patients who had more than one MII oocyte; they were classified as the "mature group". GCs were also collected from five patients who did not have MII oocytes; they were classified as the "immature group". Immature oocytes were fertilized after in vitro maturation (IVM). This study was approved by the institutional review board.

\section{Collecting granulosa cells from aspirated follicular fluid} After cumulus-oocyte complexes were collected for IVF, $20-50 \mathrm{~mL}$ of the remaining FF was centrifuged at $950 \mathrm{~g}$ for 15 minutes at room temperature. To remove most of the red blood cells, the pellet was centrifuged at $400 \mathrm{~g}$ for $20 \mathrm{~min}$ on a single-layer discontinuous Percoll gradient (50\% Ham's F12 medium, Gibco-BRL; Life Technologies, Cergy-Pontoise, France). The $50 \%$ fraction was collected and washed twice with $20 \mathrm{~mL}$ of phosphate buffered saline to remove the remaining red blood cells. Following centrifugation, the pellet was washed with fresh medium (Ham's F12). The final pellet of GCs was frozen at $-80^{\circ} \mathrm{C}$ until RNA extraction.

\section{RNA extraction and real-time PCR for microRNA}

TRIzol $^{\circledR}$ (Invitrogen, Carlsbad, CA, USA) was used for RNA extraction from the individual frozen pellets of GCs. Poly(A) tailing and complementary DNA (cDNA) synthesis for total miRNAs were performed with $100 \mathrm{pg}$ of total RNA using a commercial kit (NCode VILO miRNA cDNA Synthesis Kit, Invitrogen), according to the manufacturer's protocols (http://www.invitrogen.com) and as carried out in our previous study [16]. Quantification of miRNAs by RT-PCR was done (EXPRESS SYBR GreenER miRNA qRT-PCR Kit, Invitrogen). A two microliter reverse transcription product was used as the template, and miRNA levels were assessed using miRNA-specific PCR primers $(1 \mu \mathrm{L})$, universal miRNA reverse primers (EXPRESS SYBR GreenER miRNA qRT-PCR Kit; $1 \mu \mathrm{L}$ ), and commercial reagents (EXPRESS SYBR GreenER miRNA qRT-PCR Kit, Invitrogen; $10 \mu \mathrm{L}$ ). The total volume of the mixture for a single reaction was set to $20 \mu \mathrm{L}$ with DEPC-treated water. According to the web database (http://www.microrna.org), the miRNAs analyzed in this study are expressed in the human ovary. All of the human miRNA-specific PCR primers used in this study are listed in Table 1.

Real-time (RT) PCR was done using a Rotor-Gene instrument (Corbett Life Science, Sydney, Australia). Quantitative RT-PCR was carried out with incubation of the $20-\mu \mathrm{L}$ reaction solution (Roche, Madison, WI, USA) at $95^{\circ} \mathrm{C}$ for 15 minutes, followed by up to 62 cycles at $95^{\circ} \mathrm{C}$ for 20 seconds and at $60^{\circ} \mathrm{C}$ for 40 seconds. Expression levels of microRNAs were normalized to human U6 and the relative expression levels of miRNAs calculated as (cycle threshold value $\left[\mathrm{C}_{\mathrm{T}}\right]$ of miRNA)/(ct of control RNA) [17]. 
Table 1 List of primers used for real-time PCR of human microRNAs.

\begin{tabular}{lll}
$\begin{array}{l}\text { Primer } \\
\text { human U6 }\end{array}$ & qRT-PCR forward & qRT-PCR reverse \\
\hline hsa-let-7 a & CTCGCTTCGGCAGCACA & AACGCTTCACGAATTGCGT \\
\hline hsa-let-7b & GCGGTGAGGTAGTAGGTTGTATAGTT & universal reverse primer \\
\hline hsa-miR-16 & CCTGAGGTAGTAGGTTGTGTGGTT & universal reverse primer \\
\hline hsa-miR-26a & TAGCAGCACGTAAATATTGGCG & universal reverse primer \\
\hline hsa-miR-99a & GATTCAAGTAATCCAGGATAGGCT & universal reverse primer \\
\hline hsa-miR-125b & ACCCGTAGATCCGATCTTGTG & universal reverse primer \\
\hline hsa-miR-126 & TCCCTGAGACCCTAACTTGTGA & universal reverse primer \\
\hline hsa-miR-143 & TCGTACCGTGAGTAATAATGCG & universal reverse primer \\
\hline
\end{tabular}

Table 2 Oocyte maturity profile of subjects.

\begin{tabular}{|c|c|c|c|c|c|c|c|c|}
\hline \multirow[t]{2}{*}{ Subject } & \multirow[t]{2}{*}{ Age (years) } & \multicolumn{4}{|c|}{ Number of retrieved oocytes } & \multirow[t]{2}{*}{ 2PN } & \multirow[t]{2}{*}{ FR } & \multirow[t]{2}{*}{ Outcome } \\
\hline & & MII & MI & GV & Total & & & \\
\hline Mature 1 & 35 & 3 & 4 & 2 & 9 & 5 & $71.4 \%$ & pregnancy \\
\hline Mature 2 & 35 & 2 & 6 & - & 8 & 8 & $100.0 \%$ & pregnancy \\
\hline Mature 3 & 37 & 1 & 4 & 1 & 6 & 4 & $80.0 \%$ & pregnancy \\
\hline Mature 4 & 37 & 1 & 5 & 4 & 10 & 5 & $83.3 \%$ & pregnancy \\
\hline Mature 5 & 33 & 1 & 9 & 1 & 11 & 7 & $70.0 \%$ & pregnancy \\
\hline Immature 1 & 39 & - & 1 & 3 & 4 & 0 & $0 \%$ & no pregnancy \\
\hline Immature 2 & 37 & - & 1 & 1 & 2 & 1 & $100 \%$ & no pregnancy \\
\hline Immature 3 & 35 & - & 1 & 1 & 2 & 0 & $0 \%$ & no pregnancy \\
\hline Immature 4 & 34 & - & 1 & - & 1 & 1 & $100 \%$ & no pregnancy \\
\hline Immature 5 & 38 & - & 1 & - & 1 & 1 & $100 \%$ & no pregnancy \\
\hline
\end{tabular}

FR: fertilization rate

\section{Statistics}

Means and standard deviations were compared using MannWhitney U-test for IVF outcomes and Student's t-test for miRNA expression. Differences were considered statistically significant when the p-value was less than 0.05 . All data were analyzed using the Statistical Package for the Social Sciences for Windows software (version 12.0, SPSS Inc., Chicago, IL, USA).

\section{Results}

$\nabla$

\section{IVF outcomes}

The oocyte maturity profile of subjects is shown in Table 2. Mean age was $35.4 \pm 1.7$ years for women in the mature group and $36.6 \pm 2.1$ years for women in the immature group. Mean number of MII oocytes in the mature group was $1.6 \pm 0.9$; no MII were retrieved in the immature group $(p=0.008)$. Mean number of MI oocytes was $5.6 \pm 2.1$ in the mature group and $1.0 \pm 0.0$ in the immature group $(\mathrm{p}=0.008)$. The total number of retrieved oocytes was $8.8 \pm 1.9$ in the mature group and $2.0 \pm 1.2$ in the immature group $(\mathrm{p}=0.008)$. The mean number of two pronucleate $(2 \mathrm{PN})$ oocytes was $5.8 \pm 1.6$ in the mature group and $0.6 \pm 0.5$ in the immature group $(p=0.001)$. All women in the mature group became pregnant while none of the women in the immature group became pregnant. Two women in the immature group experienced fertilization failure ( $\bullet$ Table 2 ).

\section{Comparison of miRNAs from mature and immature oocyte groups}

The relative expression of miRNAs normalized to U6 expression in human GCs according to oocyte maturity is shown in $\bullet$ Fig. 1. GCs of MII oocytes had significantly lower expression levels of hsa-let-7b compared to GCs of MI oocytes, based on RT-PCR (5.7-fold lower, $\mathrm{p}<0.001)$. Other tested miRNAs showed no significant differences between the two groups ( $\bullet$ Fig. 1 ).

\section{Discussion \\ $\nabla$}

Recently we reported that the regulation of miRNAs in GCs modulates the meiotic competence of oocytes during in vitro maturation in a mouse follicles model [16]. In this context, the current study sought to investigate whether the expression profiles of miRNAs in human GCs differed according to the maturity of oocytes retrieved during IVF cycles. Our data showed that the GCs of MII oocytes showed lower expression levels of hsa-let-7b compared to the GCs of MI oocytes ( $\bullet$ Fig. 1 ).

When the outcome profiles of retrieved oocytes were compared, the mature group had a higher number of MII, MI and total retrieved oocytes. In this study, the GCs in FF aspirated individually from the first accessible dominant follicle reflected the respective mature or immature oocyte. Although our data did not include ovarian reserve markers such as anti-Müllerian hormone, the results imply that "mature" and "immature" groups could serve as indicators for normal and low responders, based on the number of oocytes retrieved. Further large-scale investigations are needed to investigate whether the immature cohort of retrieved 


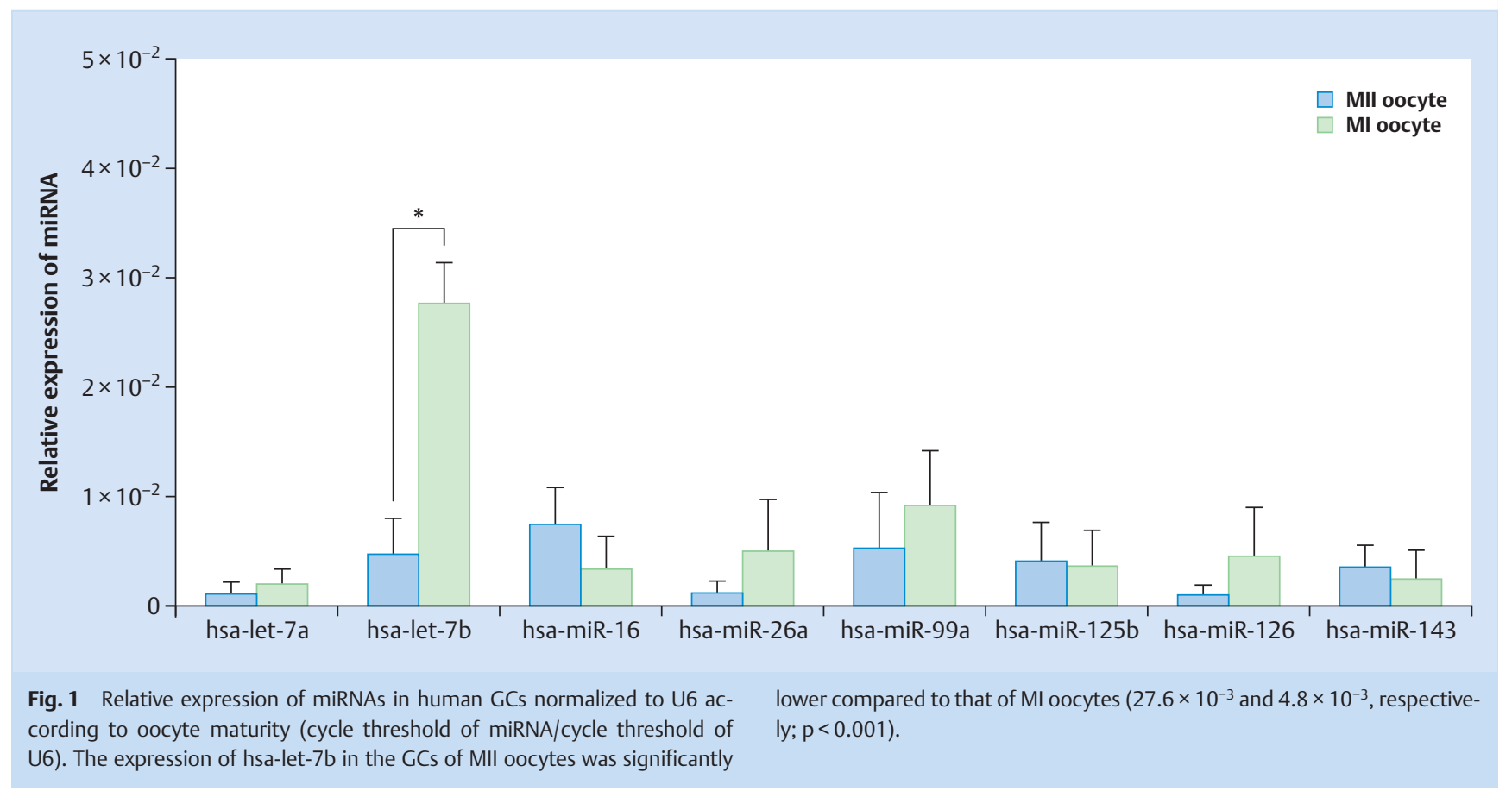

oocytes is related to lower ovarian response and whether this effect is the culmination of an insufficient expression of certain miRNAs. Some studies have suggested that the maturation of retrieved oocytes reflects the ovarian response to stimulation [18, 19].

In our results, the expression of miRNA in GCs differed according to the maturity of the oocytes. Let-7b has been reported to play an important role in the oocyte maturation process [20-22]. In previous mouse [16] and human [23] studies, the expression level of let-7b was reported to differ in GCs of MII oocytes compared to GCs of MI oocytes, which is in line with the findings of this study. Although miRNAs were previously shown to influence the meiotic competence of oocytes, further functional studies into the specific target genes of miRNAs are necessary before this strategy can be applied clinically.

Our study has some limitations. Firstly, the number of analyzed miRNAs in this study was small. We selected nine of the most highly expressed miRNAs in the human ovary based on the web database. Our data cannot rule out a possible impact of minor miRNAs expressed in the human ovary on oocyte maturation. Secondly, our data did not include a functional study of target genes of miRNAs such as a gain- and loss-of-function. However, investigations which use small amounts of human GCs from aspirated FF have a fundamental limitation with respect to mass evaluations of candidate target genes.

In conclusion, miRNA expression profiles of human GCs from dominant FF are associated with maturity of the adjacent oocyte and can be considered a potential prognosticator of outcome after IVF cycles.

\section{Funding}

This study was supported by grants from the Ministry of Health and Welfare, Republic of Korea (HI14C2289 and HI14C2259) and the 2012 Bumsuk Academic Research Fund.

\section{Conflict of Interest}

$\nabla$

The authors declare they have no existing or potential conflicts of interest.

\section{References}

1 Swain JE, Pool TB. ART failure: oocyte contributions to unsuccessful fertilization. Hum Reprod Update 2008; 14: 431-446

2 Zhang M, Su YQ Sugiura K et al. Granulosa cell ligand NPPC and its receptor NPR2 maintain meiotic arrest in mouse oocytes. Science 2010; 330: 366-369

3 Russell DL, Robker RL. Molecular mechanisms of ovulation: co-ordination through the cumulus complex. Hum Reprod Update 2007; 13: 289-312

4 Adriaenssens T, Mazoyer C, Segers I et al. Differences in collagen expression in cumulus cells after exposure to highly purified menotropin or recombinant follicle-stimulating hormone in a mouse follicle culture model. Biol Reprod 2009; 80: 1015-1025

5 Pacella L, Zander-Fox DL, Armstrong DT et al. Women with reduced ovarian reserve or advanced maternal age have an altered follicular environment. Fertil Steril 2012; 98: 986-994.e1-2

6 Yerushalmi GM, Maman E, Yung Y et al. Molecular characterization of the human ovulatory cascade-lesson from the IVF/IVM model. J Assist Reprod Genet 2011; 28: 509-515

7 Gebhardt KM, Feil DK, Dunning KR et al. Human cumulus cell gene expression as a biomarker of pregnancy outcome after single embryo transfer. Fertil Steril 2011; 96: 47-52.e2

8 Bartel DP. MicroRNAs: target recognition and regulatory functions. Cell 2009; 136: 215-233

9 Ratner E, Lu L, Boeke $M$ et al. A KRAS-variant in ovarian cancer acts as a genetic marker of cancer risk. Cancer Res 2010; 70: 6509-6515

10 Lee PD, Giudice LC, Conover CA et al. Insulin-like growth factor binding protein-1: recent findings and new directions. Proc Soc Exp Biol Med 1997; 216: 319-357

11 Lai EC. miRNAs: whys and wherefores of miRNA-mediated regulation. Curr Biol 2005; 15: R458-R460

12 Boutet S, Vazquez F, Liu J et al. Arabidopsis HEN1: a genetic link between endogenous miRNA controlling development and siRNA controlling transgene silencing and virus resistance. Curr Biol 2003; 13: 843-848

13 Poy MN, Eliasson L, Krutzfeldt J et al. A pancreatic islet-specific microRNA regulates insulin secretion. Nature 2004; 432: 226-230 
14 Sokol NS, Ambros V. Mesodermally expressed Drosophila microRNA-1 is regulated by Twist and is required in muscles during larval growth. Genes Dev 2005; 19: 2343-2354

15 He L, Hannon GJ. MicroRNAs: small RNAs with a big role in gene regulation. Nat Rev Genet 2004; 5: 522-531

$16 \mathrm{Kim}$ YJ, Ku SY, Kim YY et al. MicroRNAs transfected into granulosa cells may regulate oocyte meiotic competence during in vitro maturation of mouse follicles. Hum Reprod 2013; 28: 3050-3061

17 Torley KJ, da Silveira JC, Smith P et al. Expression of miRNAs in ovine fetal gonads: potential role in gonadal differentiation. Reprod Biol Endocrinol 2011; 9: 2

18 Ozdegirmenci O, Dilbaz S, Cinar O et al. Can serum oestradiol be a predictor of quality of oocytes and embryos, maturation of oocytes and pregnancy rate in ICSI cycles? Gynecol Endocrinol 2011; 27: 279-285
19 Moria A, Das M, Shehata F et al. Ovarian reserve and oocyte maturity in women with malignancy undergoing in vitro maturation treatment. Fertil Steril 2011; 95: 1621-1623

20 Otsuka $M$, Zheng $M$, Hayashi $M$ et al. Impaired microRNA processing causes corpus luteum insufficiency and infertility in mice. J Clin Invest 2008; 118: 1944-1954

21 Miles JR, McDaneld TG, Wiedmann RT et al. MicroRNA expression profile in bovine cumulus-oocyte complexes: possible role of let-7 and miR-106a in the development of bovine oocytes. Anim Reprod Sci 2012; 130: 16-26

22 Christenson LK. MicroRNA control of ovarian function. Anim Reprod 2010; 7: 129-133

23 Assou S, Al-Edani T, Haouzi D et al. MicroRNAs: new candidates for the regulation of the human cumulus-oocyte complex. Hum Reprod 2013; 28: $3038-3049$ 